\title{
Structural integrity analysis and experimental investigation for solid rocket motor grain subjected to low temperature ignition
}

\author{
Zhi-Bin Shen ${ }^{\mathrm{a}}$, Liang Zhang ${ }^{\mathrm{b}}$ and Yi-Fei $\mathrm{Li}^{\mathrm{c}}$ \\ College of Aeronautics and Astronautics, National University of Defense Technology, Changsha, Hunan 410073, P.R. China \\ ab_shen@yeah.net, bliangzi0403@126.com, ${ }^{\mathrm{C}} 50618276 @ q q . c o m$
}

\begin{abstract}
The structural integrity of solid rocket motor(SRM) grain is severely tested owing to the combined action of low temperature and pressure load under the load case of low temperature ignition. The three dimensional finite element model of SRM was created to analyze the structural integrity of the SRM grain subjected to low temperature and ignition pressure based on three dimensional viscoelastic finite element method via MSC.Patran/Marc. Meanwhile, cold pressurization test was applied on certain SRM. The experimental result and numerical result were compared based on uncoupling principal of temperature and pressure. The result show that the safety factor of solid rocket motor grain is 2.46 which can meet the requirement of structural integrity. The experimental results are in good agreement with the simulation results. Relevant research methods and conclusions can provide reference for the design, analysis and test of SRMs.
\end{abstract}

\section{Introduction}

Solid rocket motor(SRM) owns many advantages such as simple structure, high reliability, long storage life, easy to use when compared to liquid rocket motor[1]. This is why it is widely used in the aerospace industry. For the safety issue, structural integrity destruction is the main cause for the failure of solid rocket motor. Thus the research on structural integrity of solid rocket motor is one of the most important subject for the development of solid rocket technology. Numerical analysis is one of the most cost effective way to analyze the mechanical response of solid rocket motor under varies loading conditions. However, the results from numerical analysis can be ideal and corresponding experiment should be applied to verify the result $[2,3]$.

From the published results[4], the worst working condition for solid rocket motor is low temperature ignition. This working condition is always applied to determine the structural integrity of solid rocket motor. In this study, the three dimensional finite element model of star grain was created by MSC.Patran/Marc according to the actual test of solid rocket motor under low temperature. The structural integrity analysis was performed under low temperature ignition based on three dimensional viscoelastic model. The result from numerical simulation was validated by cold pressurization test. It can be used for the reference of failure mechanism analysis of solid rocket motor trial under low temperature.

\section{Computational model}

\subsection{Modelling.}

The research focuses on star grain. The model is made up of metal case, thermal insulation layer and solid grain. Only 1/8 model was created because of symmetry. The created finite element model include 27016 hexahedral elements and 48458 nodes as is indicated in figure 1 .

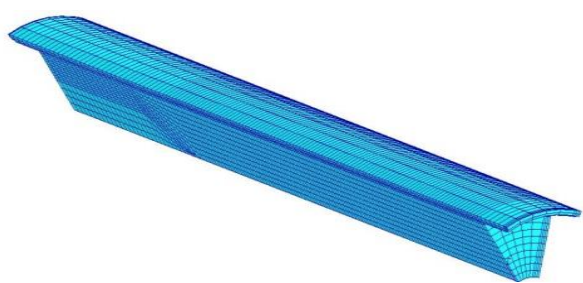

Figure .1 Three dimensional finite model of SRM

\subsection{Material parameter}

For simplicity, it is assumed that the propellant is linear viscoelastic material which is isotropic, uniform and with constant Poisson's ratio. The motor case and thermal insulation layer are assumed as elastic material. The Prony series of shear relaxation modulus $G(t)$ and volume relaxation modulus $K(t)$ are adopted to describe the constitutive equation of linear viscoelastic material[5]. If

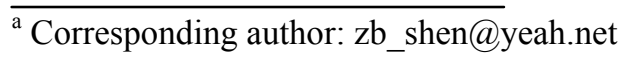


the Possion's ratio is independent to time, Then the relationship among $G(t), K(t)$ and tensile relaxation modulus $E(t)$ can be described as

$$
E(t)=2 G(t)(1+v)=3 K(t)(1-2 v)
$$

The Prony series of $E(t)$ can be described as

$$
E(t)=E_{0}-\sum_{i=1}^{n_{E}} E_{i}\left(1-e^{-\frac{t}{\tau_{i}}}\right)
$$

where $E_{0}$ is the initial tensile relaxation modulus, $n_{E}$ is the number of terms, $E_{i}$ and $\tau_{i}$ are factors of $E(t)$. The tensile relaxation modulus $E(t)$ can be obtained by uni-axial tensile relaxation experiment as is described in Table.1, where $i=5$.

Tabel 1 Coefficient of propellant tensile relaxation modulus $E(t)$

\begin{tabular}{cccccc}
\hline$i$ & 1 & 2 & 3 & 4 & 5 \\
\hline$E_{i}$ & 3.05 & 1.42 & 1.04 & 0.47 & 0.40 \\
$\tau_{i}$ & 0.01 & 0.03 & 0.96 & 31.78 & 1055.69 \\
\hline
\end{tabular}

Note: Initial modulus $E_{0}=21.44 M P a$

The temperature shift factor $a_{T}$ of the propellant can be propellant unidirectional tensile test. described in WLF function The material properties of motor case, thermal insulation $\lg a_{T}=\frac{-C_{1}\left(T-T_{S}\right)}{C_{2}+T-T_{S}}$ layer and propellant are listed in Table 2.

where the reference temperature $T_{S}=273.15 \mathrm{~K}$. $C_{1}=23.79$ and $C_{2}=455.01$ are obtained through

Table 2 Material parameters of SRM components

\begin{tabular}{l}
$\begin{array}{c}\text { Elastic modulus } \\
\text { Case }\end{array}$ \\
$\begin{array}{l}\text { Insulation layer } \\
\text { propellant grain }\end{array}$ \\
\hline \\
$\begin{array}{l}\text { I } \\
\text { Boundary conditions and loading cases. }\end{array}$ \\
The axial displacement constraint is applied on the front-end \\
of motor case while the circumferential displacement \\
constraint is applied on the motor side surface. \\
The curing temperature of composite solid propellant is $50^{\circ} \mathrm{C}$ \\
while the zero-stress temperature is $58^{\circ} \mathrm{C}$. It is assumed that \\
the propellant temperature decreases gradually from \\
zero-stress temperature to room temperature $20^{\circ} \mathrm{C}$ with the \\
speed of $1{ }^{\circ} \mathrm{C} / \mathrm{h}$. From room temperature $20^{\circ} \mathrm{C}$ to low \\
temperature $-40^{\circ} \mathrm{C}$, the speed for temperature decreasing is \\
$10^{\circ} \mathrm{C} / \mathrm{h}$. Then the motor is ignited in $0.1 \mathrm{~s}$ and the peak value \\
of inner pressure is $10.4 \mathrm{MPa}$.
\end{tabular}

\subsection{Evaluated criterion of structural integrity}

Under the temperature loading and inner pressure loading, Von Mises strain criterion is usually applied as the criterion for structural integrity of solid propellant[6]

$$
\varepsilon_{v} \leq \frac{\varepsilon_{v m}}{n}
$$

where, $\varepsilon_{v m}$ is strain critical value and $n$ is the safety factor. The expression of Von Mises strain is $\varepsilon_{v}=\frac{\sqrt{2}}{3} \sqrt{\left(\varepsilon_{x}-\varepsilon_{y}\right)^{2}+\left(\varepsilon_{y}-\varepsilon_{z}\right)^{2}+\left(\varepsilon_{z}-\varepsilon_{x}\right)^{2}+\frac{3}{2}\left(\varepsilon_{x y}^{2}+\varepsilon_{x z}^{2}+\varepsilon_{y z}^{2}\right)}$

Under maximum stretch, the strains can have following
Coefficient of thermal expansion

Poission's ratio / $\left(1 /{ }^{\circ} \mathrm{C}\right)$

$\begin{array}{ll}0.3 & 1.10 \times 10^{-5} \\ 0.498 & 2.95 \times 10^{-4} \\ 0.498 & 8.60 \times 10^{-5}\end{array}$
expressions $\varepsilon_{y}=\varepsilon_{z}=-v \varepsilon_{x}, \varepsilon_{x}=\varepsilon_{m}, \varepsilon_{x y}=\varepsilon_{y z}=\varepsilon_{x z}=0$,

Then

$$
\varepsilon_{v m}=\frac{2}{3}(1+v) \varepsilon_{m}
$$

where $\varepsilon_{m}$ is the maximum elongation of the propellant.

In this paper, Von Mises strain criterion is used as the criterion for evaluating structural integrity in view of the convenience of obtaining $\varepsilon_{m}$ and $\varepsilon_{v}$ [7]. The commercial FEM software MSC.Marc is used as a solver in the simulation.

\section{Results and discussion}

Temperature loads and pressure loads both applied on the motor during ignition under low temperature. During numerical analysis, the temperature load is applied first and then pressure load is imposed. The Von Mises strain distribution under temperature load of $-40^{\circ} \mathrm{C}$ is shown in Fig.2. As can be seen from Figure2, the maximum Von Mises strain under $-40^{\circ} \mathrm{C}$ is $15.0 \%$ which is located at the intersection of transition section and tube section.

Under combined loading, with $-40^{\circ} \mathrm{C}$ temperature load and 10.4MPa pressure load, the Von Mises strain distribution is given in Fig.3. The location with the maximum Von Mises strain is the same with only temperature load applied, the maximum Von Mises strain is $19.4 \%$.

The principal curve for elongation under $-40^{\circ} \mathrm{C}$ can be 
obtained from fitting through measurement of maximum elongation of standard samples with different stretching rate under $-40^{\circ} \mathrm{C}$ as can be seen from Fig.4. Under low temperature, the elongation of propellant decreases with the increasing of strain rate. The safety factor can be obtained by allowable strain which is calculated by strain rate and temperature shift factor[8]. The safety factor is 2.46 according to $-40^{\circ} \mathrm{Ctemperature} \mathrm{load} \mathrm{and} 10.4 \mathrm{MPa}$ pressure load, it means the motor meet the requirement of structural integrity.

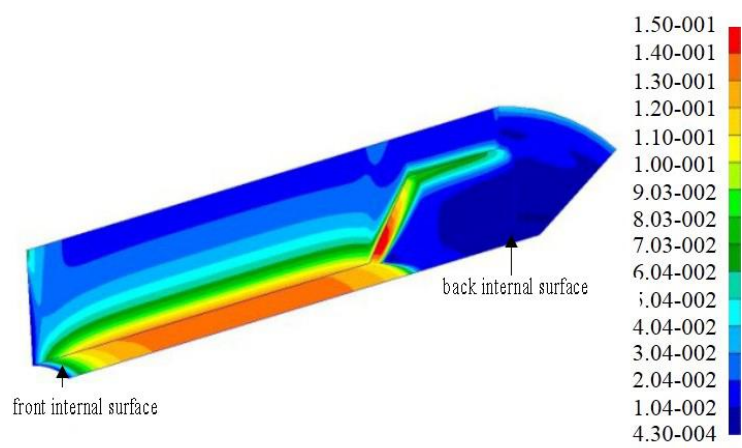

Figure 2 Von Mises strain distribution of grain under low temperature loading of $-40^{\circ} \mathrm{C}$

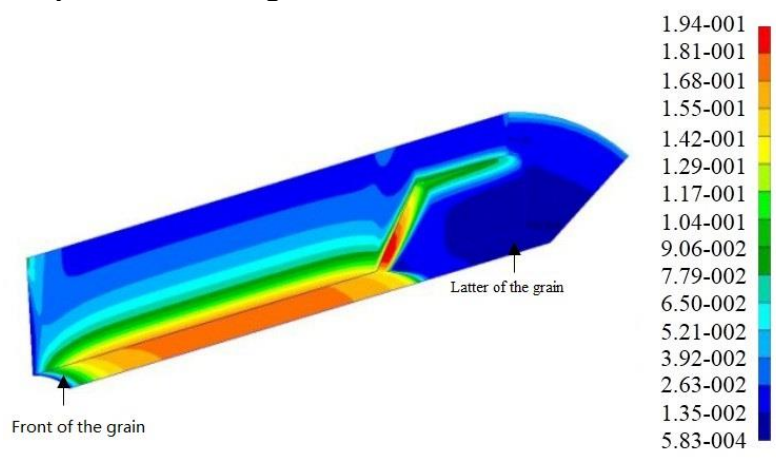

Figure 3 Von Mises strain distribution of grain under combined loading of $-40^{\circ} \mathrm{C}$ and $10.4 \mathrm{MPa}$ ignition pressurization

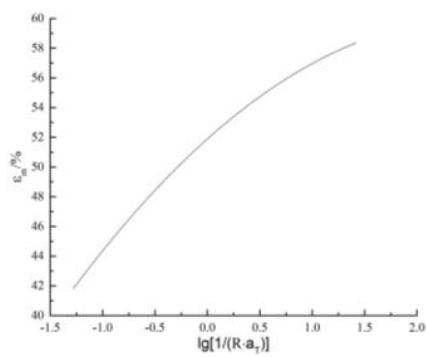

Figure.4 Elongation main cure of propellant at $-40^{\circ} \mathrm{C}$

\section{Validation}

The designed cold pressurization testing system is used for validating the numerical result. The schematic diagram for the system is shown in Fig.5. The system mainly includes four sections. They are fast pressurizing device, strain measurement system, pressure monitoring and valve control system, data collecting and processing. The main function for the system is to increase the pressure from 0 to $15 \mathrm{MPa}$ in
$200 \mathrm{~ms}$. The measuring deviation of pressure sensor is within $1 \%$ and the response time is lower than $1 \mathrm{~ms}$.

In order to measure the strain response of the motor during pressurizing stage, the strain gages are placed at the inner side of tube section and star section for collecting the data in an accurate way. The locations for strain gages are shown in Fig.6.

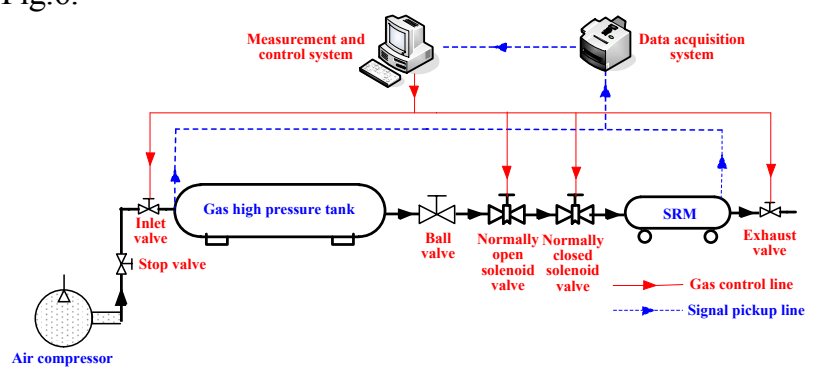

(a) Schematic diagram

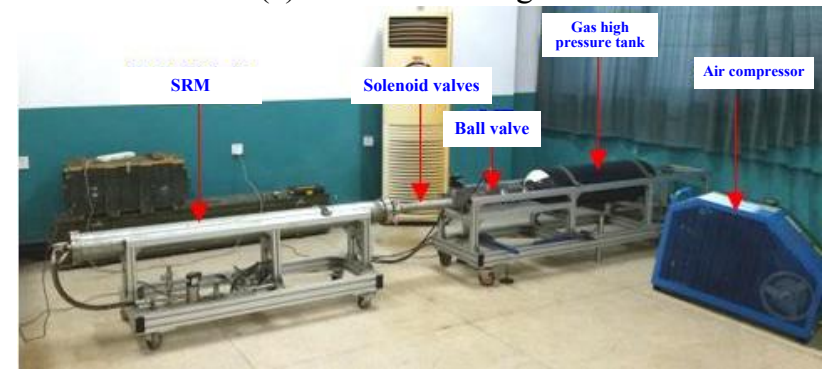

(b) Object diagram

Figure.5 Cold pressurization testing system for SRM
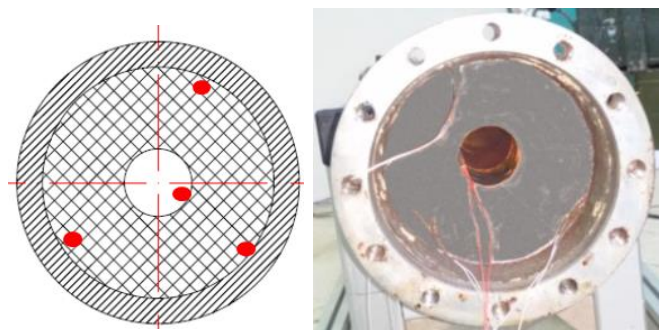

(a) strain measuring point in front of the grain
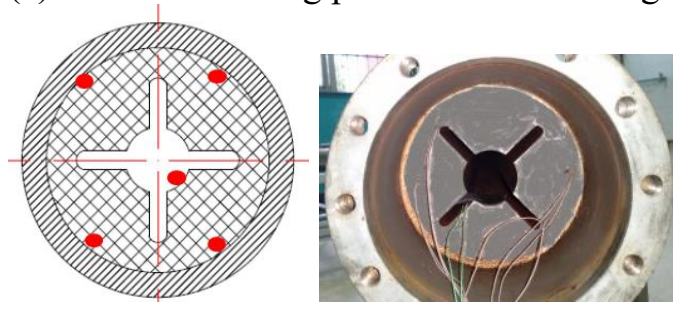

(b) strain measuring point in latter of the grain

Figure 6 Location of grain strain measurint points

The pressure variation for gas cylinder and simulated motor during pressurizing is shown in Fig.7. It can be seen that the pressure for the gas cylinder decreases in the beginning and then fluctuate in a small range. The reason may be attributed to the existence of air swirl during ignition under low temperature. For the simulated motor, the pressure increases from 0 to $10.4 \mathrm{MPa}$ in $120 \mathrm{~ms}$ and peaks at $10.6 \mathrm{MPa}$ after another $10 \mathrm{~ms}$. Then the pressure decreases gradually. Considering the capacity and control accuracy of loading pressure, the pressure change for simulated motor can be considered as meeting the requirement for the test.

The strain variation for inner surface of simulated motor is 
shown during pressurizing in Fig.8 through data collecting and processing. The maximum strain equals to $1.95 \%$ appears at fore inner surface in $130 \mathrm{~ms}$ while the latter inner surface delays for about $35 \mathrm{~ms}$ and maximum strain appears at $165 \mathrm{~ms}$. It may be owing to the pressurizing process which is from the front to the end.

According to the reseach from Liu et.al [9], there are no intercoupling between temperature load and pressure load. The maximum strain is superimposed, which means the maximum strain is the summation for the maximum strain under temperature load and pressure load. Based on this conclusion, the strain variation under ignition at different location can be calculated separately. For validation, the strain at the front and the end are obtained at $120 \mathrm{~ms}$ under pressure of $10.4 \mathrm{MPa}$. The compared data is shown in Table 3. Good agreement between numerical analysis and experiment can be seen. The error is only $5.73 \%$ for front inner surface while is $10.71 \%$ for the latter inner surface. But the absolute error is less than $0.5 \%$. The bigger error for latter inner hole may be attributed to the lag of response for the latter surface during pressurization.

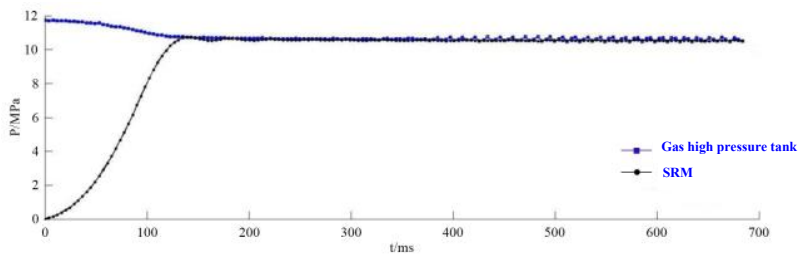

Figure 7 p-t curve of gas cylinder and simulated SRM

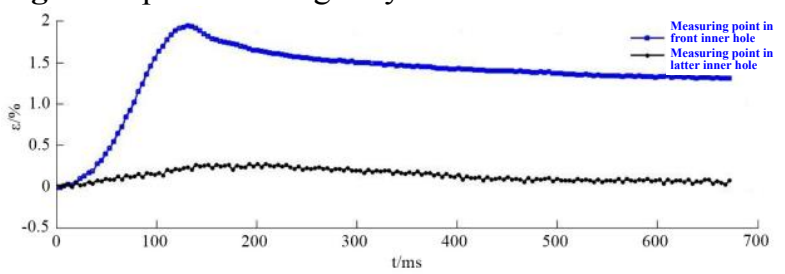

Figure $8 \varepsilon$-t curve of front and rear inner surface of simulated motor

Table 3 Results comparison of simulation and cold pressurization test

\begin{tabular}{cccccc}
\hline & $\begin{array}{c}\text { Temperature load } \\
\text { applied solely }\end{array}$ & $\begin{array}{c}\text { Combined } \\
\text { load }\end{array}$ & $\begin{array}{c}\text { Pressure load } \\
\text { applied solely }\end{array}$ & $\begin{array}{c}\text { Cold Pressurizing } \\
\text { test } / \%\end{array}$ & $\begin{array}{c}\text { Relative } \\
\text { error }\end{array}$ \\
\hline $\begin{array}{c}\text { Front inner } \\
\text { hole }\end{array}$ & 7.03 & 9.06 & 2.03 & 1.92 & $5.73 \%$ \\
$\begin{array}{c}\text { Latter inner } \\
\text { hole }\end{array}$ & 1.04 & 1.35 & 0.31 & 0.28 & $10.71 \%$ \\
\hline
\end{tabular}

\section{Conclusion}

To evaluate the structural integrity of a certain SRM under the load case of low temperature ignition, the three dimensional finite element model of SRM was created to analyze the structural integrity of the SRM grain subjected to low temperature and ignition pressure. Our results were confirmed by the cold pressurization test. The main conclusions are as follows:

Under combined loading, with $-40^{\circ} \mathrm{C}$ temperature load and $10.4 \mathrm{MPa}$ pressure load, the maximum Von Mises strain is shown up at the junction of transition section and star section. The maximum Von Mises strain is $19.4 \%$ and the safety factor is 2.46. The requirement for structural integrity is satisfied.

The cold pressurizing testing system can increase the pressure from 0 to $10.4 \mathrm{MPa}$ in $120 \mathrm{~ms}$. It indicates that the system can be used for simulating the ignition process of solid rocket motor.

The good agreement can be found when comparing results from the numerical analysis and test based on the non-intercoupling between temperature load and pressure load. The proposed method can be applied to different cases related to motor ignition under low temperature.

\section{References}

1. R.X. Chen. Design and research of solid rocket motor. Beijing: Aerospace Publishing House, 1991.
2. G. J. Tang, Z.B. Shen, X. C. Song. Design and application of cold pressurization testing system for solid rocket motor[J]. Journal of Solid Rocket Technology, 2011, 34(4): 423-425.

3. Z.B. Liu, Y.Q.Zhou. Simulation experiment technology for low temperature ignition adaptability of solid rocket motor[J]. Journal of Solid Rocket Technology, 2015, 38(2): 203-207.

4. K.Q. Deng, L. Zhang, A.M.Pang. Analysis on structural integrity of a free loading solid propellant grains under ignition loading at low temperature. Journal of Solid Rocket Technology, 2018, 41(4): 428-434.

5. Z.B. Shen, R.W. Jiang, S.J. Zhi. Effects of umbrella slot on the structure integrity of solid rocket motor grain with large aspect ratio. Journal of National University of Defense Technology, 2017, 39(1): 148-152.

6. L. Zhang, G.Q. Xing. The Analysis for Grain Structural Integrity of a Certain Solid Rocket Motor. Aero Weaponry, 2012, 2: 29-32.

7. M.Liu, B. Gao, X.J. Dong. Failure criterion of solid motors at ignition pressurization loading. Journal of Solid Rocket Technology, 2018, 41(4): 424-427.

8. S.X. Song, H.B. Shi, Z.B. Liu. Structural analysis of solid rocket motor grain at ignition transient under low temperature. Journal of Solid Rocket Technology, 2018, 41(3): 278-283.

9. Z.B. Liu, Y.Q. Zhou, B. Zhang. Structural integrity analysis on grains of solid rocket motor at low temperature ignition. Journal of Solid Rocket Technology, 2015, 38(3): 351-354. 